\title{
Atmospheric impact of Arctic Sea ice loss in a coupled ocean-atmosphere simulation
}

Article

Published Version

Open Access

Petrie, R. E., Shaffrey, L. C. and Sutton, R. T. (2015) Atmospheric impact of Arctic Sea ice loss in a coupled oceanatmosphere simulation. Journal of Climate, 28 (24). pp. 96069622. ISSN 1520-0442 doi: https://doi.org/10.1175/JCLI-D-150316.1 Available at https://centaur.reading.ac.uk/51159/

It is advisable to refer to the publisher's version if you intend to cite from the work. See Guidance on citing.

Published version at: http://dx.doi.org/10.1175/JCLI-D-15-0316.1

To link to this article DOI: http://dx.doi.org/10.1175/JCLI-D-15-0316.1

Publisher: American Meteorological Society

All outputs in CentAUR are protected by Intellectual Property Rights law, including copyright law. Copyright and IPR is retained by the creators or other copyright holders. Terms and conditions for use of this material are defined in the End User Agreement.

www.reading.ac.uk/centaur

\section{CentAUR}


Central Archive at the University of Reading

Reading's research outputs online 


\title{
əAtmospheric Impact of Arctic Sea Ice Loss in a Coupled Ocean-Atmosphere Simulation*
}

\author{
Ruth E. Petrie, Len C. Shaffrey, And Rowan T. Sutton \\ NCAS-Climate, Department of Meteorology, University of Reading, Reading, United Kingdom
}

(Manuscript received 30 April 2015, in final form 31 July 2015)

\begin{abstract}
The atmospheric response to an idealized decline in Arctic sea ice is investigated in a novel fully coupled climate model experiment. In this experiment two ensembles of single-year model integrations are performed starting on 1 April, the approximate start of the ice melt season. By perturbing the initial conditions of sea ice thickness (SIT), declines in both sea ice concentration and SIT, which result in sea ice distributions that are similar to the recent sea ice minima of 2007 and 2012, are induced. In the ice loss regions there are strong $(\sim 3 \mathrm{~K})$ local increases in sea surface temperature (SST); additionally, there are remote increases in SST in the central North Pacific and subpolar gyre in the North Atlantic. Over the central Arctic there are increases in surface air temperature (SAT) of $\sim 8 \mathrm{~K}$ due to increases in ocean-atmosphere heat fluxes. There are increases in SAT over continental North America that are in good agreement with recent changes as seen by reanalysis data. It is estimated that up to two-thirds of the observed increase in SAT in this region could be related to Arctic sea ice loss. In early summer there is a significant but weak atmospheric circulation response that projects onto the summer North Atlantic Oscillation (NAO). In early summer and early autumn there is an equatorward shift of the eddy-driven jet over the North Atlantic as a result of a reduction in the meridional temperature gradients. In winter there is no projection onto a particular phase of the NAO.
\end{abstract}

\section{Introduction}

Arctic sea ice has been in decline since approximately the start of the satellite era (circa 1979) when observations of the sea ice extent became more widely available (Comiso 2012). The rate of decline of sea ice extent has increased from $\sim 4 \%$ decade $^{-1}$ between 1978 and 2010 to $\sim 8.3 \%$ decade $^{-1}$ between 1996 and 2010 (Comiso 2012). Sea ice is a physical barrier between the ocean and atmosphere that modulates the ocean-atmosphere fluxes of heat, moisture, and momentum. The reduction of Arctic sea ice from the

๖ Denotes Open Access content.

\footnotetext{
* Supplemental information related to this paper is available at the Journals Online website: http://dx.doi.org/10.1175/JCLI-D-150316.s1.

Corresponding author address: Ruth E. Petrie, Dept. of Meteorology, Whiteknights Campus, University of Reading, Reading RG6 6BB, United Kingdom.

E-mail: r.e.petrie@reading.ac.uk
}

September mean value of $\sim 7.5 \times 10^{6} \mathrm{~km}^{2}$ in the early 1980 s to $\sim 3.5 \times 10^{6} \mathrm{~km}^{2}$ in 2012 (NSIDC 2012) implies that there will be associated changes in the surface fluxes (Porter et al. 2012). Changes in the surface fluxes are not restricted to the time of maximum ice loss; rather, it has been shown by Deser et al. (2010), for example, that the largest surface fluxes occur in late autumn and early winter when the ocean-atmosphere temperature gradient is greatest. It is predicted that as emissions of greenhouse gases (GHGs) continue throughout this century the Arctic will warm at a rate faster than the global mean temperature; this is known as Arctic amplification (AA; see, e.g., Winton 2006; Collins et al. 2013). As a result it is predicted that the Arctic will become seasonally ice free (defined as less than $1 \times 10^{6} \mathrm{~km}^{2}$ in ice extent) at some time during the middle of this century (Stroeve 2012). The extent to which recent changes in the Arctic may have the potential to affect the large-scale atmospheric circulation has become an active area of research in recent years, and numerous studies (see discussion below) of reanalysis data and model simulations have sought to address this question. For a comprehensive review of the effects of Arctic sea ice decline on the large-scale 
atmospheric circulation, see Cohen et al. (2014), Vihma (2014), and Budikova (2009).

Recent studies of reanalysis data, such as Francis et al. (2009), Honda et al. (2009), Jaiser et al. (2012), Liu et al. (2012), and Tang et al. (2013), have suggested that anomalously low Arctic sea ice in autumn precedes a negative phase of the North Atlantic Oscillation-Arctic Oscillation (NAO-AO) in winter. This implies that anomalously cold Eurasian winters may be linked to declines in Arctic sea ice. Liu et al. (2012) and Overland et al. (2011) suggest that reduced Arctic sea ice in the Barents and Kara Seas increases the midtropospheric heights in this region in winter, and a downstream trough occurs over central Eurasia, resulting in a cooling of the Eurasian continent. Francis and Vavrus (2012, 2015) suggest that as a result of AA (which is greatest in winter) there is a reduction in the meridional temperature gradient that leads to slower, higher-amplitude planetary waves and an increased likelihood of persistent weather patterns. However, Screen and Simmonds (2013) find that the link between AA and changes in planetary waves is sensitive to the metric used to define the waves and do not find robust changes in planetary waves in winter, though there are indications that in summer there are detectable changes. Studies of reanalysis data are limited; they can identify correlations and covariability but cannot assign causality.

Climate modeling studies provide a framework within which declines in Arctic sea ice can be prescribed and causality can be more readily determined. There have been a number of modeling studies seeking to identify the atmospheric response to declines in Arctic sea ice and there have been a range of results reported in the literature (Deser et al. 2010; Cohen et al. 2014). For example, Magnusdottir et al. (2004), Deser et al. (2004), and Peings and Magnusdottir (2014) find that anomalously low Arctic sea ice in autumn is followed by a negative phase of the NAO-AO. However, Deser et al. (2010) find a negative mean sea level pressure (MSLP) response over the central Arctic in early winter and negligible changes in midwinter; only in February is there a projection onto the negative phase of the NAO. Singarayer et al. (2006) find a positive AO response in winter to anomalously low Arctic sea ice in autumn. Screen et al. (2013) and Petrie et al. (2015) find that the winter response to anomalously low Arctic sea ice in autumn is smaller than natural variability.

In summer the atmospheric circulation response to Arctic sea ice decline is smaller in magnitude than in winter. However, summer has a smaller range of natural variability and therefore changes in circulation may be more readily detectable. Tang et al. (2014) (a study of ERA-Interim data) suggest that the loss of Arctic sea ice, combined with the reduction in Northern Hemisphere snow cover, weakens the upper-level zonal winds and induces a higher-amplitude, poleward-shifted jet stream that increases the likelihood of extreme summer weather over the northern midlatitudes. The modeling studies of Balmaseda et al. (2010), Screen (2013), Knudsen et al. (2015), and Petrie et al. (2015) all suggest a link between declines in Arctic sea ice and northwestern European summer climate. Screen (2013) finds a link between the reduction in Arctic sea ice and increased summer rainfall over northern Europe. Balmaseda et al. (2010), Knudsen et al. (2015), and Petrie et al. (2015) suggest that declines in Arctic sea ice may be associated with the negative phase of the summer NAO (Folland et al. 2009).

The majority of modeling studies investigating the impacts of Arctic sea ice decline on the large-scale atmospheric circulation have been atmosphere-only experiments (e.g., Alexander et al. 2004; Singarayer et al. 2006; Seierstad and Bader 2009; Deser et al. 2010; Petrie et al. 2015; among many others). These studies have not accounted for ocean-atmosphere interactions and so may not capture the full atmospheric response to declines in Arctic sea ice. In addition, each experiment prescribes different sea ice concentration (SIC) and sea surface temperature (SST) boundary conditions for their control and perturbation experiments. Some studies have attempted to account for the local changes in SST due to the loss of sea ice (e.g., Balmaseda et al. 2010; Screen et al. 2013; Peings and Magnusdottir 2014), which can be as much as $5 \mathrm{~K}$ locally, as observed in 2007 (Perovich et al. 2008). One unaddressed question is whether the differences in the specification of the lower boundary condition in atmosphere-only experiments contribute to the very large diversity of responses seen in the atmospheric circulation (Cohen et al. 2014). A natural extension to using atmosphereonly simulations to investigate the large-scale atmospheric response to Arctic sea ice decline is to utilize ocean-atmosphere coupled climate model simulations. To date, only a few ocean-atmosphere coupled experiments investigating the loss of Arctic sea ice have been performed, such as Graversen and Wang (2009), Scinocca et al. (2009), and Deser et al. (2015). Graversen and Wang (2009) discuss the role of surface albedo feedbacks in Arctic amplification, Scinocca et al. (2009) discuss the stratospheric response, and Deser et al. (2015) discuss the role of ocean feedbacks and zonal mean atmospheric response to Arctic sea ice loss. These coupled simulations allow for potentially important ocean-atmosphere interactions that are not permitted in an atmosphere-only simulation. A question to be addressed is whether experiments that allow 
for coupled ocean-atmosphere interactions might have qualitatively different responses from those seen in atmosphere-only experiments.

The aim of this study is to investigate the large-scale atmospheric response to an idealized decline in Arctic sea ice within a fully coupled simulation. This simulation fully accounts for ocean-atmosphere coupling through the fluxes of heat, moisture, and momentum, as well as local changes in SST in response to Arctic sea ice loss. However, to investigate the impact of Arctic sea ice loss, an alternative method of inducing sea ice melt within a coupled modeling framework must be found. This can be done by altering the surface albedo of the sea ice (Scinocca et al. 2009) or forcing sea ice melt through increased longwave radiative flux (Deser et al. 2015). Since recent declines in Arctic sea ice are characterized by not only declines in sea ice concentration but also declines in sea ice thickness (SIT; Polyakov et al. 2012), in this modeling experiment the approach taken is to artificially thin the Arctic sea ice at the start of the melt season. This novel approach to investigating the atmospheric response to Arctic sea ice loss is a physically consistent approach, negating the need to specify the SIC and SST boundary conditions, and fully accounts for local SST changes in response to melting sea ice and ocean-atmosphere interactions.

The rest of this paper is structured as follows: Section 2 discusses the experimental methodology, including a description and evaluation of the model and the experimental design. Section 3 presents recent observed changes of SIC, SIT, SST, and surface air temperature (SAT) in the Arctic. Section 4 presents the model responses to the perturbation experiment, considering the local and remote thermodynamic responses and circulation responses. Section 5 provides a summary and conclusions.

\section{Methodology}

Section 2a provides a description of the model used in the numerical simulations and an evaluation of its ability to simulate the mean state of some key variables. Section $2 \mathrm{~b}$ describes the experimental design in detail.

\section{a. Model description and evaluation}

In this experiment the Global Climate Model version 2.0 (GC2.0) of the Met Office Unified Model (UM) is used (Williams et al. 2015). The atmospheric resolution is N96L85 (i.e., a horizontal resolution of $1.25^{\circ} \times 1.85^{\circ}$ with 85 vertical levels extending up to $\sim 85 \mathrm{~km}$ ). This atmospheric component is coupled to version 3.4 of the Nucleus for European Modelling of the Ocean (NEMO) ocean model (Madec 2008) and version 4.1 of the Los Alamos sea ice model (CICE) with five ice categories (Hunke and Lipscomb 2008). Both NEMO and CICE have a $0.25^{\circ}$ horizontal resolution, and NEMO has 75 vertical levels. In this study we provide an evaluation of the key variables: SIC, SIT, and SST [for a full assessment of GC2.0, see Williams et al. (2015)].

In Fig. 1 observationally derived data averaged over the reference period 1981-2000 for SIC, SIT, and SSTs are compared with the mean of the model control run. Two different two-monthly periods are evaluated: (i) the April-May (AM) mean, which approximates the start of the ice melt season, and (ii) August-September (AS), which approximates the sea ice minimum. Figures $1 \mathrm{a}-\mathrm{d}$ show that the model representation of the SIC distributions in AM and AS are in good agreement with the HadISST data. There are biases in SIC in AS where the model has a tendency to overestimate the SICs in the marginal seas surrounding the central Arctic and underestimate the SIC to the east of the North Pole.

Figures $1 \mathrm{e}-\mathrm{h}$ show that there are biases in the model representation of the SIT distributions when compared with the Pan-Arctic Ice Ocean Modeling and Assimilation System (PIOMAS; Zhang and Rothrock 2003; Schweiger et al. 2011) estimates of sea ice thickness. In AM at the start of the melt season the model overestimates the SIT in the Beaufort, Chukchi, East Siberian, and Laptev Seas by between 1 and $3 \mathrm{~m}$. These biases in SIT imply that it is less likely that extreme sea ice minima (as have been seen in recent years) would be simulated through internal variability alone. In AS sea ice of $O(1.5) \mathrm{m}$ extends across the Arctic basin. The PIOMAS model of the AS distribution of SIT estimates that the thickest ice of $O(3) \mathrm{m}$ is pushed up against the Canadian archipelago and Greenland and that SIT then decreases in depth across the Arctic to the Siberian coast. The model does not capture this structure, having sea ice that is too thin along the coast of the Canadian archipelago and Greenland and too thick in the region of the Chukchi and East Siberian Seas.

Figures $1 \mathrm{i}-1$ show that the model representations of the SST distributions (for the entire Northern Hemisphere) are in reasonable agreement with the HadISST data. In AM the model has cool SST biases in the North Atlantic and central North Pacific when compared with the HadISST data. In AS the cool bias is more prominent in the central North Pacific with a reasonable distribution of SSTs in the North Atlantic. The Northern Hemisphere cold biases are common among the general circulation models (GCMs) used in phase 5 of the Coupled Model Intercomparison Project (CMIP5; Wang et al. 2014). 
April-May

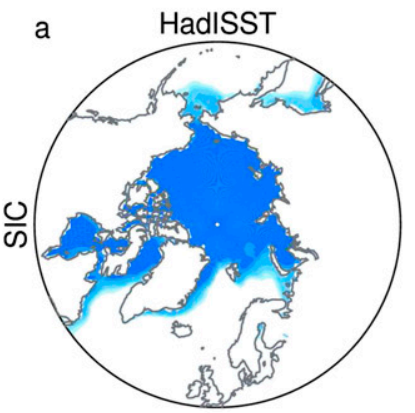

b

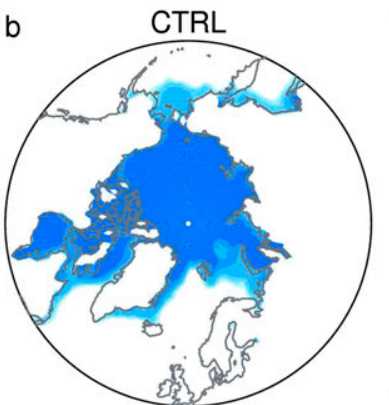

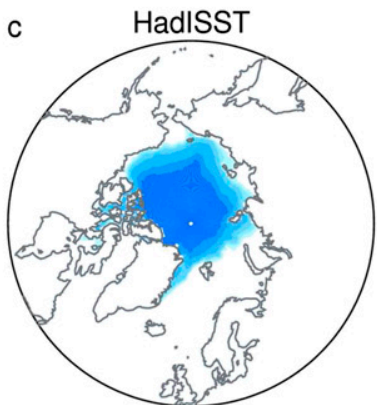


0.1

0.3

0.5

0.8

0.9

Fractional sea ice concentration (0-1)
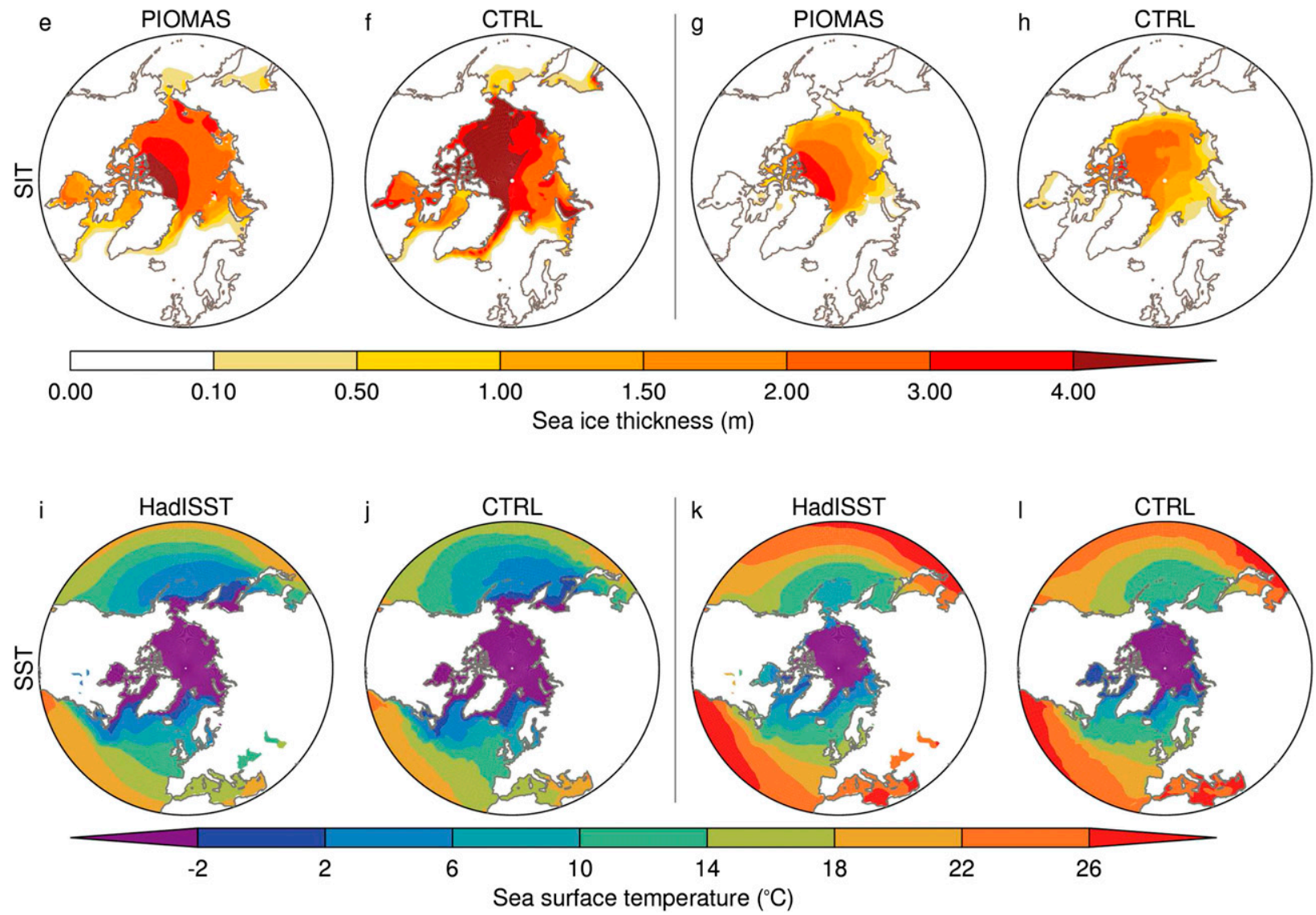

FIG. 1. The mean states of the observational derived data are compared with the model control for AM (two left columns) and AS (two right columns). The model is compared with HadISST data for (a)-(d) SIC and (i)-(1) SST, and the model is compared against PIOMAS data for (e)-(h) SIT. SIC and SIT are shown from $50^{\circ}$ to $90^{\circ} \mathrm{N}$, and SSTs are shown from $0^{\circ}$ to $90^{\circ} \mathrm{N}$.

\section{b. Experimental design}

The aim of this model experiment is to investigate the impact of Arctic sea ice loss on the atmosphere within a fully coupled system. The initial conditions of the SIT field at the start of the melt season are perturbed so that during the seasonal cycle the sea ice declines to give an SIC minimum anomaly approximating the minima seen in recent observations. Only the SIT is perturbed; the SIC is unchanged. Perturbing the initial conditions of 

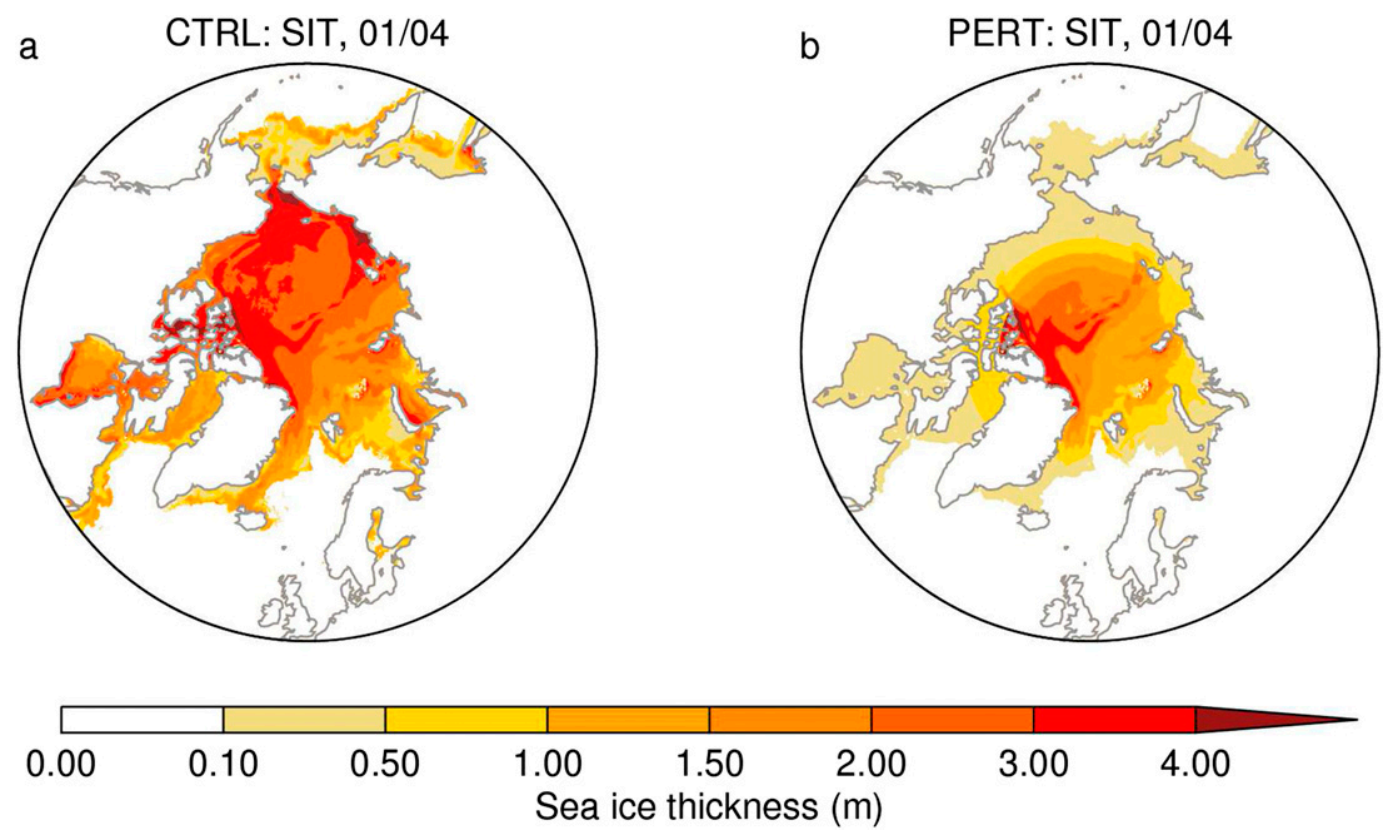

FIG. 2. The model initial conditions of SIT distribution on 1 April for (a) the control experiment and (b) the perturbation experiment from $50^{\circ}$ to $90^{\circ} \mathrm{N}$.

SIT at the start of the melt season within the fully coupled system is a physically consistent way to induce low sea ice extents at the seasonal minimum, as recent declines in Arctic sea ice are characterized by declines in both SIC and SIT (Polyakov et al. 2012).

The integrations begin on 1 April from a previously spun-up present-day control run (which was evaluated in section 2a) and are then integrated for one year. A control experiment (CTRL) is performed where no SIT perturbation is applied, and a perturbation experiment (PERT) is performed with perturbed SIT initial conditions. The same initial conditions of SIC and SSTs are used in both CTRL and PERT; both experiments use the same present-day annual cycle of GHGs and aerosols. Each experiment is an ensemble of 30 members. The different ensemble members are initialized by using 30 different atmospheric initial conditions. Both CTRL and PERT use the same ensemble of atmospheric initial conditions.

Figures 2a,b show the ensemble-mean SIT distributions for CTRL and PERT, respectively. Figure $2 b$ shows how the SIT has been artificially thinned at the start of the melt season (1 April). Below $72^{\circ} \mathrm{N}$ all ice covered data points are set to be $10 \mathrm{~cm}$ thick with all the sea ice assigned to the first ice category of CICE; this ensures that sea ice outside of the central Arctic and sea ice in the marginal seas melt during the integration. In the Canadian archipelago ice is set to be $50 \mathrm{~cm}$; again, this sea ice is assigned to the first ice category. Sea ice (in each of the five ice categories of CICE) in the Fram
Strait is linearly thinned from $80^{\circ}$ to $72^{\circ} \mathrm{N}$. Between $72^{\circ}$ and $80^{\circ} \mathrm{N}$ in the central Arctic, sea ice is first reduced to $70 \%$ of its original value in each of the five ice categories and then linearly thinned from $80^{\circ}$ to $72^{\circ} \mathrm{N}$. The perturbation applied to SIT is a way of inducing anomalously low SICs at the sea ice minimum in September. Although the perturbation in SIT is quite large as a result of the SIT biases in CTRL, the atmospheric response to a first order will be dominated by the presence or absence of ice rather than the ice thickness.

\section{Recently observed changes in the Arctic}

The Arctic region has been changing rapidly in recent years. Some of the recent changes that have occurred are shown in Fig. 3. The differences shown are the mean of the recent low-ice period (2007-13) relative to the mean of the reference period (1981-2000). Stippled regions indicate where the signal-to-noise ratio is greater than 1.0; the signal-to-noise ratio is defined as the difference divided by $1.0 \sigma$ (one standard deviation) of the twomonthly period. No signal-to-noise ratio is plotted on the SIT field, as nearly all points have a signal-to-noise ratio greater than 1.0; the only exceptions are in the East Siberian and Laptev Seas.

Figures 3a-e show the differences in SIC in the recent period relative to the reference period from the ERAInterim data (Dee et al. 2011). The reduction in SIC that has been well documented (see, e.g., Comiso 2012) can be clearly seen by a loss of SIC in the Barents and Kara 



FIG. 3. Recent changes in the Arctic region from 2007 to 2013 are shown relative to the reference period 1981-2000 from $50^{\circ}$ to $90^{\circ} \mathrm{N}$. Differences are shown for (a)-(e) SIC, (f)-(j) SIT, (k)-(o) SST, and (p)-(t) SAT. Data are taken from ERA-Interim for SIC, SST, and SAT (for consistency) and from PIOMAS for SIT. The differences shown are for two-monthly means JJ, AS, ON, DJ, and FM. The recent changes from 2007 to 2013 are shown relative to the reference period 1981-2000. Panels (a)-(e) show SIC differences taken from the HadISST dataset (from $50^{\circ}$ to $90^{\circ} \mathrm{N}$ ), where the gray contour shows the climatological position of the sea ice (i.e., where the SIC is greater than 0.15 in the reference period). Stippling indicates where the signal-to-noise ratio (difference divided by one standard deviation of the two-monthly period) is greater than 1.0. No signal-to-noise is plotted on the SIT field, as all points with the exception of in the East Siberian and Laptev Seas have a signal-to-noise ratio greater than 1.0. 
Seas in winter and a loss of ice in all the marginal seas surrounding the central Arctic in the summer and autumn.

Figures $3 \mathrm{f}-\mathrm{j}$ shows the differences in SIT. The SIT data are from the PIOMAS dataset. CryoSat-2 has shown that the SIT estimates from PIOMAS give a reasonable estimation of the SIT (Laxon et al. 2013). Figures $3 \mathrm{f}-\mathrm{j}$ show that there have been declines in SIT in all seasons across the entire Arctic basin. This is in contrast to the SIC, which shows limited declines over the winter months. The largest declines in thickness over the Beaufort, Chukchi, East Siberian, and Laptev Seas are in summer and autumn. This is consistent with the findings of Polyakov et al. (2012) and is indicative of the decline of multiyear thick ice in favor of thinner firstyear ice.

Figures $3 \mathrm{k}$-o shows the differences in SST from ERAInterim data. Regions of warming that have a signal-tonoise ratio greater than 1.0 are seen in the Atlantic at high latitudes and in the region of the Barents and Kara Seas. These warm differences are likely due in part to the rapid warming in the North Atlantic in the early 1990s (e.g., Palmer and Haines 2009; Sarafanov et al. 2008), with a component due to a forced response from anthropogenic warming (Collins et al. 2013). Positive SST anomalies in the North Atlantic may have played a role in enhancing the decline of Arctic sea ice, particularly in the Labrador, Barents, and Kara Seas (Smedsrud et al. 2013). In the central North Pacific there are warm SST differences, and along the west coast of North America there are cool SST differences; this pattern projects onto the negative phase of the Pacific decadal oscillation (PDO).

Figures $3 \mathrm{p}-\mathrm{t}$ show the differences in SAT from ERAInterim data. A clear signal of warm differences in the recent low-ice period compared with the reference period over the regions of ice loss is seen from August to February. In June-July (JJ) the heat flux is from the atmosphere to the ocean and so available energy is used to melt ice and warm the upper ocean (Serreze and Barry 2011); in other months, the heat flux is from the ocean to the atmosphere, leading to warm SAT differences. However the warming is not confined to the regions of ice loss. In JJ, AS, and October-November (ON) there are widespread continental positive SAT differences; regions where the signal-to-noise ratio is greater than 1.0 are limited to northeastern North America and central Eurasia. In December-January (DJ) there is a signal of Eurasian continental cooling. This is consistent with the warm Arctic-cold continents (WACC) pattern (Overland et al. 2011), which consists of positive temperature anomalies over the Arctic and negative temperature anomalies over the continental midlatitudes. A similar pattern can be seen in JanuaryFebruary (JF), but the cold differences are at higher latitudes and have limited regions where the signal-tonoise ratio is greater than 1.0 .

\section{Model responses}

In this section the model responses in the PERT experiment are considered as the ensemble-mean differences of PERT relative to the ensemble mean of CTRL. Results are presented as two-monthly means to allow for a comparison between the early and late seasonal responses. They are ordered as follows: section 4a discusses the response of the SIT, section $4 \mathrm{~b}$ discusses the thermodynamic responses, and section $4 \mathrm{c}$ discusses the atmospheric circulation responses. The vertical structure of the temperature and salinity responses in the Arctic, Atlantic, and Pacific Oceans are shown in the supplementary material.

\section{a. Evolution of sea ice thickness}

Figure 4 shows the two-monthly ensemble means of the spatial evolution of the SIT distribution throughout the full year of integration for CTRL, PERT, and the difference. Stippling indicates that the difference is statistically significant at the $95 \%$ level using a Student's $t$ test. Figures $4 \mathrm{~g}-1$ show that as the experiment progresses the artificially thinned ice melts preferentially (with an induced loss of SIC; see section 4b, Fig. 5). Over the year of integration the ice melts in a way that resembles the recent observed sea ice distributions as shown by the SICs in Figs. 3a-e. The AS sea ice coverage approximates the spatial distribution of the lowest observed sea ice years, 2007 and 2012 (e.g., Comiso et al. 2008; Walsh 2013). Note that the sea ice in Hudson Bay has completely melted away by JJ, which differs from recent observations. During the recent low-ice period it is not until at least August that sea ice in Hudson Bay melts away (Fig. 3g). In subsequent analysis of the model response to this perturbation, AM will not be considered. In AM most of the Arctic remains ice covered (see Fig. 4g), and therefore ocean-atmosphere fluxes are small in this season.

\section{b. Thermodynamic responses}

Figure 5 shows the responses of SIC, SST, SAT, and the total turbulent surface heat flux [latent and sensible ( $\mathrm{L}+$ S) surface heat flux] in the PERT experiment as twomonthly ensemble means from JJ to FM. Figures 5a-e show the SIC declines in response to the PERT experiment; the largest declines are seen in Hudson Bay in JJ and in the marginal seas in JJ, AS, and ON. The seasonal evolution of the SIC decline approximates the observed 

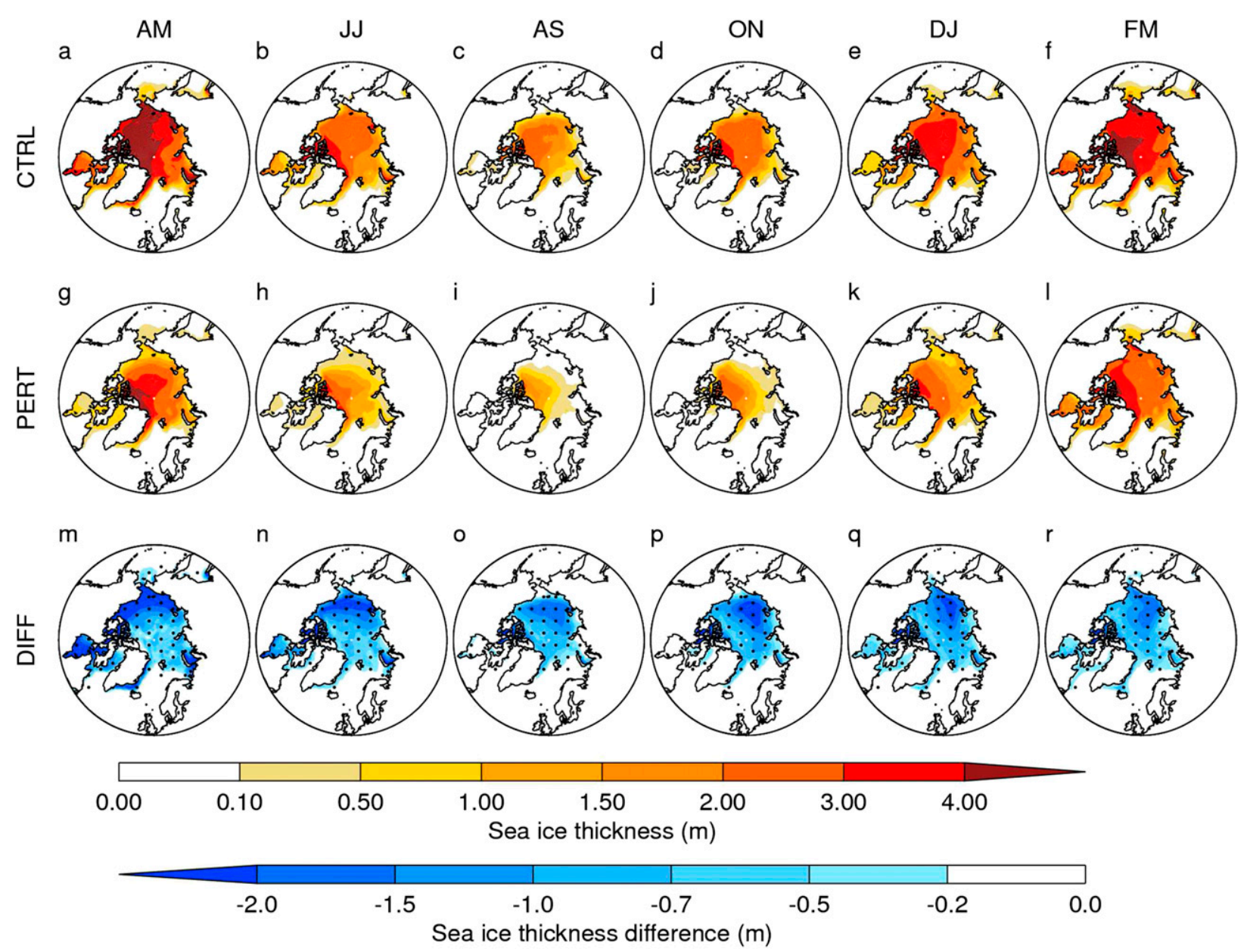

FIG. 4. Two-monthly means of the SIT distribution for (a)-(f) CTRL, (g)-(l) PERT, and (m)-(r) the difference (DIFF) from $50^{\circ}$ to $90^{\circ} \mathrm{N}$. Stippling in (m)-(r) indicates where differences are significant at the $95 \%$ level from a Student's $t$ test.

declines that have been seen over the recent low-ice period (cf. Figs. 3a-e).

Figures $5 \mathrm{f}-\mathrm{j}$ show that there are both local and remote increases in SSTs in the Northern Hemisphere in the PERT experiment. The local responses are where icecovered regions in CTRL become ice free in PERT and are therefore collocated with the declines in SIC. Where sea ice is lost, open water warms because of direct radiative absorption, resulting in an increase in SST. The statistically significant SST increases are in Hudson Bay and the marginal seas surrounding the central Arctic, with the largest increases seen in AS and ON with a magnitude of $\sim 3 \mathrm{~K}$. The warming is not confined to the surface but is present throughout the mixed layer. These large increases in SST in the marginal seas are present only in AS in the reanalysis data (Fig. 31). In the model simulation the ice has been reduced more extensively than during the observed recent low-ice period and the warm SSTs persist into ON. These large increases in SST highlight the importance of correct specification of SIC and SST boundary conditions in any atmosphere-only experiment investigating the impacts of sea ice decline. An atmosphere-only experiment that does not account for local increases in SSTs of $\sim 3 \mathrm{~K}$ in regions of ice loss will underestimate the SST forcing from sea ice loss. Remote increases in SST are seen in both the Atlantic and Pacific. Increases in SST in AS, ON, and DJ in the North Atlantic can be seen in Hudson Bay and the Labrador Sea and reach as far south as the subpolar gyre. In the central North Pacific, increases in SST are seen down to $50^{\circ} \mathrm{N}$. This remote warming cannot be explained through the process of melting ice exposing the sea surface and allowing direct radiative absorption and therefore must be driven by another process; this will be discussed after consideration of the SAT and surface heat fluxes.

Figures $5 \mathrm{k}-\mathrm{O}$ show that there are again both local and remote increases in SAT. There are local increases in SAT in JJ in Hudson Bay, the Labrador Sea, and the Bering Strait. From AS to FM there are both local and 

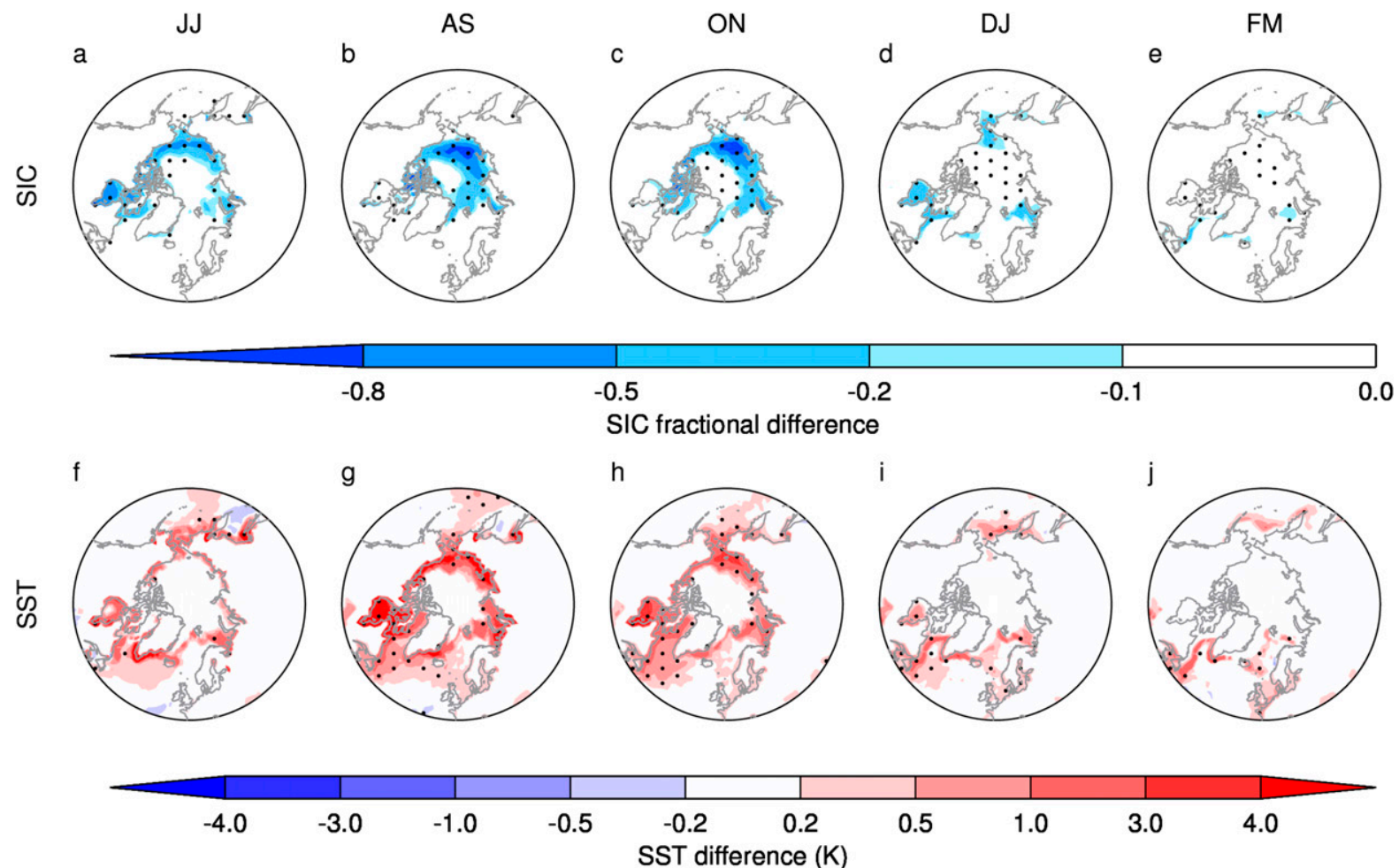

$\mathrm{k}$
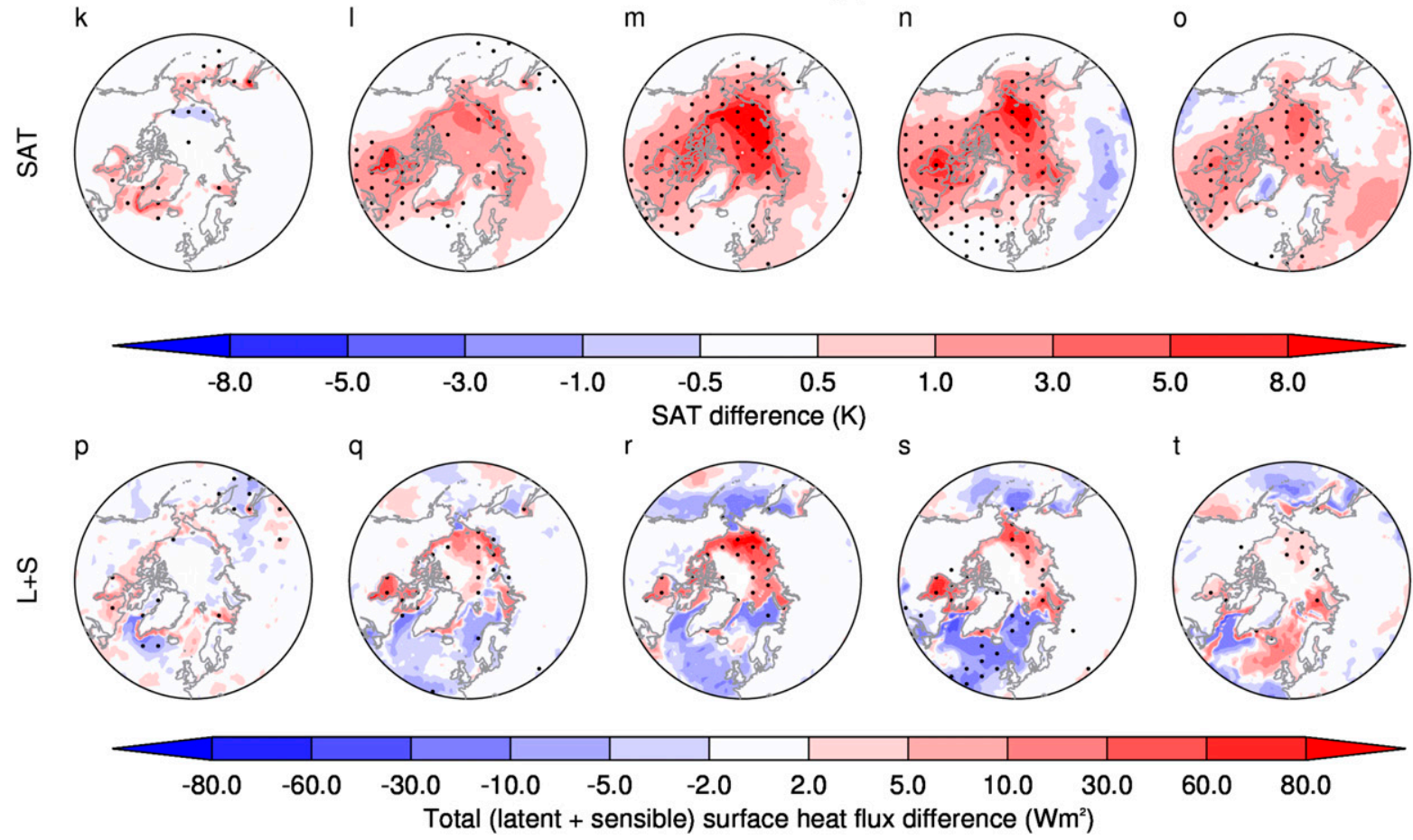

FIG. 5. Two-monthly means of model response differences (PERT - CTRL) of (a)-(e) SIC, (f)-(j) SST, (k)-(o) SAT, and (p)-(t) L + S surface heat flux from $45^{\circ}$ to $90^{\circ} \mathrm{N}$. Stippling indicates where the response is significant at the $95 \%$ level from a Student's $t$ test.

remote increases in SAT. In AS the largest temperature increases are restricted to the regions of ice loss (i.e., a local response), though temperature increases can be seen across the Arctic basin and over continental North
America and Eurasia. The largest increases in SAT over the Arctic is in ON with increases of $\sim 8-10 \mathrm{~K}$, and increases in SAT persist into DJ $(\sim 5-8 \mathrm{~K})$ and FM $(\sim 2 \mathrm{~K})$. During ON and DJ the large increases in SAT are not 
confined to the regions of ice loss; they extend over the entire Arctic basin and spread south over continental North America and to a limited extent over Siberia. This is in contrast to Petrie et al. (2015), where in an atmosphere-only sea ice loss experiment it was found that the SAT increases were spatially limited to the regions of ice loss, indicating that the role of oceanatmosphere coupling is important in generating the widely distributed positive temperature response. It is interesting to note that the spatial distribution of increases in SAT seen in the model over the central Arctic and over North America are similar to those seen in the recent low-ice period (cf. Figs. 3p-t). The central Arctic warming is approximately 1.5 times greater in the model than in the reanalysis; for example, in ON and DJ the local increases in SAT in the model are $\sim 8-10 \mathrm{~K}$, whereas the ERA-Interim estimate is $\sim 5-8 \mathrm{~K}$. The North American continental warming in the model and the reanalysis data are of a similar magnitude $(\sim 1 \mathrm{~K})$. This implies that up to two-thirds of the North American continental warming in the recent period may be a response to the recent decline in Arctic sea ice. In the model the SAT increases are driven by the loss of Arctic sea ice. In ON and DJ the changes in the top-ofatmosphere radiative balance are small compared with the changes in total surface fluxes (not shown), and therefore the heat released from the ocean in the regions of sea ice loss in autumn and early winter must be exported southward out of the Arctic (Shaffrey and Sutton 2006). In the reanalysis data other factors such as increased radiative forcings or increases in GHGs among others could have contributed to the continental North American increase in SAT. Therefore the estimate of the contribution of sea ice loss to the continental North American increase in SAT is an upper limit. In DJ there is a region of continental Eurasian cooling at lower latitudes that is similar to the warm Arctic-cold continents pattern (Overland et al. 2011) and the recent observed changes (Fig. 3s), though it is smaller in magnitude and spatial extent and is not statistically significant at the 95\% level.

Figures $5 p-t$ show that there are positive $\mathrm{L}+\mathrm{S}$ surface heat fluxes in the regions of sea ice loss, indicating an ocean-to-atmosphere heat flux. The positive $\mathrm{L}+\mathrm{S}$ surface heat fluxes to the atmosphere begin in AS in conjunction with the start of the ice growth season and persists through to FM. The most prominent positive $\mathrm{L}+\mathrm{S}$ surface heat fluxes are in ON and DJ where there are heat fluxes in excess of $60 \mathrm{~W} \mathrm{~m}^{-2}$ in the marginal seas of the central Arctic where the ice loss is greatest. The largest surface heat fluxes do not coincide with the sea ice minimum in September; rather, they occur later in the season in autumn and early winter when the ocean-atmosphere temperature gradient is greatest, which is consistent with Deser et al. (2010). Other regions such as Hudson Bay and the Labrador, Barents, and Kara Seas also show positive $\mathrm{L}+\mathrm{S}$ surface heat fluxes. There are regions outside of the central Arctic where $\mathrm{L}+\mathrm{S}$ is negative (i.e., the flux of heat is from atmosphere to ocean); these regions include the North Atlantic and North Pacific but most notably occur in the eastern North Atlantic in DJ. Where sea ice is lost during the melt season the open water absorbs additional heat, and during the autumn and early winter this additional heat is then released back to the atmosphere. The changes in the top-ofatmosphere radiative balance in autumn and early winter are small compared with the changes in the total surface fluxes (not shown). Therefore, the spatial pattern of turbulent surface heat fluxes are indicative of a southward export of heat from the Arctic to the North Atlantic and North Pacific by the atmosphere where it warms the subpolar and midlatitude oceans and land (Shaffrey and Sutton 2006). (Note that the time scale in this experiment is too short for an advective response in ocean as each ensemble member is only a single-year integration of the model.) This is reflected in the increase in SSTs in the North Atlantic and North Pacific that are outside of the regions of ice loss and in the midlatitude continental SAT increases.

Figures $6 \mathrm{a}-\mathrm{e}$ show the zonal mean temperatures as a function of latitude (from $0^{\circ}$ to $90^{\circ} \mathrm{N}$ ) and height (from 900 to $200 \mathrm{hPa}$; the lowest levels are not included to exclude orographic effects). Positive temperature responses with a large vertical extent are most pronounced and statistically significant at the 95\% level in AS, ON, and DJ. In AS at the start of the ice growth season there are positive temperature responses $(\sim 1 \mathrm{~K})$ that are statistically significant from approximately $50^{\circ}$ to $80^{\circ} \mathrm{N}$ and extend up to $\sim 400 \mathrm{hPa}$. In ON the statistically significant response is from approximately $60^{\circ}$ to $90^{\circ} \mathrm{N}$. Between $60^{\circ}$ and $70^{\circ} \mathrm{N}$ the warm responses $(\sim 1 \mathrm{~K})$ reach $\sim 500 \mathrm{hPa}$. At higher latitudes from $70^{\circ}$ to $90^{\circ} \mathrm{N}$ temperature increases in excess of $1 \mathrm{~K}$ are seen but extend up to only $\sim 700 \mathrm{hPa}$. In DJ the extent of the positive temperature response is again reduced, extending up to $\sim 600 \mathrm{hPa}$ between $60^{\circ}$ and $70^{\circ} \mathrm{N}$ and $\sim 800 \mathrm{hPa}$ between $70^{\circ}$ and $90^{\circ} \mathrm{N}$. In summer the Arctic boundary layer inversion is weaker and higher than in winter (Serreze and Barry 2005). In AS this weaker inversion allows the Arctic $\left(60^{\circ}-90^{\circ} \mathrm{N}\right)$ troposphere to warm to greater depths (e.g., through turbulent mixing) than in $\mathrm{ON}$ and DJ when the inversion is stronger and lower.

Figures $7 \mathrm{a}-\mathrm{e}$ shows the zonal mean precipitation responses (from $30^{\circ}$ to $90^{\circ} \mathrm{N}$ ) as a percentage of the zonal mean average; the crosses denote responses that are statistically significant at the $95 \%$ level. In JJ there is a 

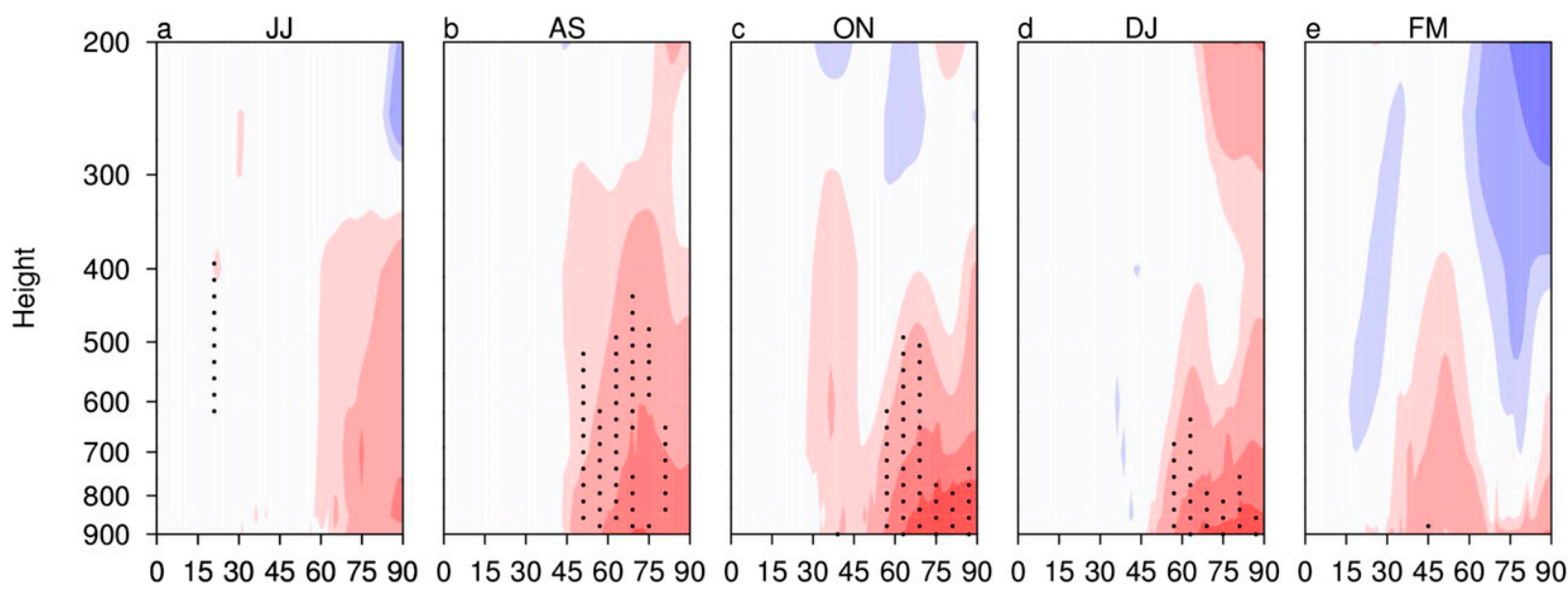

Latitude

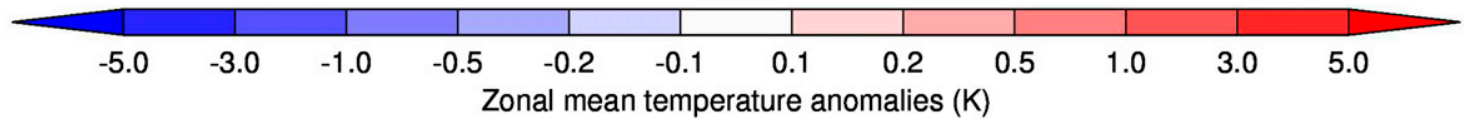

FIG. 6. Temperature anomalies as a function of latitude and height in the free troposphere (900-200 hPa). Stippling indicates where the response is significant at the $95 \%$ level from a Student's $t$ test.

significant $\sim 5 \%$ increase in precipitation around $60^{\circ} \mathrm{N}$. In AS this increases to $10 \%-15 \%$. In ON there is a $\sim 30 \%$ increase in precipitation north of $80^{\circ} \mathrm{N}$, with statistically significant increases between $5 \%$ and $30 \%$ between $65^{\circ}$ and $80^{\circ} \mathrm{N}$; a similar response is seen in DJ, but the percentage increase in precipitation is lower. As a result of the reduction in sea ice there is a flux of moisture as well as a flux of heat from the ocean to the atmosphere (shown in AS, ON, and DJ in Figs. 51-n and 6b-d) in the ice growth seasons. Sea ice melt increases moisture availability and induces greater ocean-to-atmosphere heat fluxes, which lead to positive tropospheric temperature anomalies (Fig. 6). The warmer atmosphere at high latitudes therefore has a greater relative humidity, which implies increased precipitation. Comparing the increase in SAT in the central Arctic (i.e., north of $70^{\circ} \mathrm{N}$ ) there is a $\sim 5 \%$ increase in precipitation per $1 \mathrm{~K}$ increase in SAT.

Figures $8 \mathrm{a}-\mathrm{e}$ show Arctic $\left(70^{\circ}-90^{\circ} \mathrm{N}\right)$ average cloud fraction responses. The only statistically significant responses are in AS and ON. In AS, there is a $10 \%-15 \%$ decrease near the surface and a $\sim 5 \%$ increase in fractional cloud cover between 1000 and $1500 \mathrm{~m}$. In ON there is a $5 \%-10 \%$ decrease in cloud cover near the surface and a $5 \%-15 \%$ increase between 500 and $2000 \mathrm{~m}$. The pattern of decreases and increases of fractional cloud cover in the lower atmosphere reflect the lower-tropospheric positive temperature anomalies (Fig. 6) and represent a deepening of the Arctic boundary layer. In AS and ON there are small increases in net surface shortwave radiation (not shown) of approximately $10 \mathrm{~W} \mathrm{~m}^{-2}$ in the Arctic. These are much smaller than the turbulent surface heat fluxes (Figs. 5q,r), implying that changes in the turbulent surface fluxes are dominating the model response.

Figures 9a-e show the Northern Hemisphere continental snow-cover responses. Greenland shows a decline in snow cover around the perimeter across all seasons, which is consistent with recent observations of the declining Greenland ice sheet (Hall et al. 2013). In ON, DJ, and FM, there is a general decline in the Canadian snowpack and the central Eurasian snowpack, with statistically significant increases in snow cover being restricted to northeastern Eurasia. The spatial pattern of snow cover is qualitatively similar to Deser et al. (2010). The spatial patterns of declines in the autumn and winter snow cover over North America are consistent with the increases in SAT seen in Fig. 5. The increase in the snow cover over northeastern Eurasia might be consistent with the mean flow (the Siberian high) advecting anomalously moist air from the Arctic southward where the increased precipitation falls as snow. The model shows a general decline in the central Eurasian snow cover in autumn through increases in SAT; this implies that a decrease in Eurasian snow cover may be a response to the loss of Arctic sea ice.

\section{c. Atmospheric circulation responses}

Figure 10 shows the two-monthly responses for MSLP, geopotential height at $500 \mathrm{hPa}$ (Z500), and zonal wind at $850 \mathrm{hPa}$ (U850). In JJ (Fig. 10a) there is an anticyclonic response in MSLP over Greenland and the 


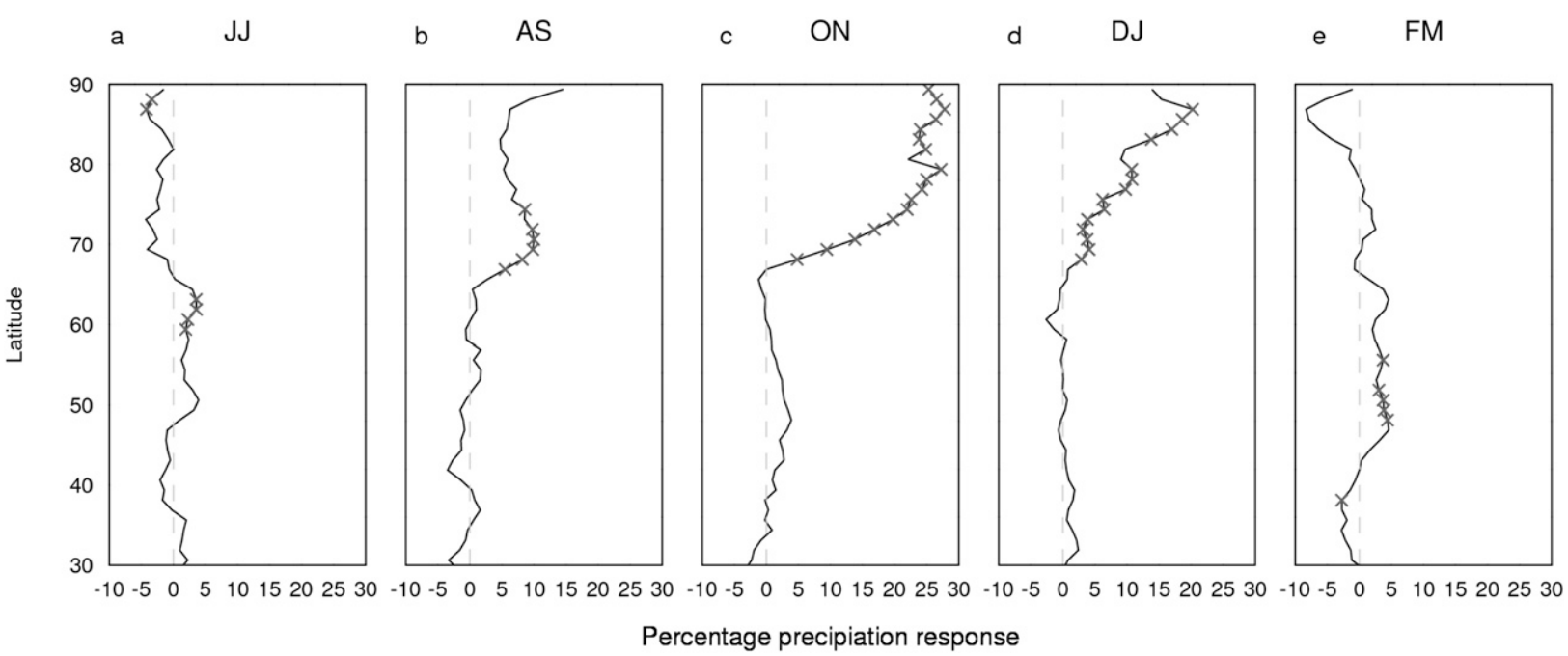

FIG. 7. Two-monthly means of zonal mean precipitation responses as a percentage difference from CTRL. Crosses denote statistically significant responses at the $95 \%$ level from a Student's $t$ test. Vertical dashed lines are used to indicate the $0 \%$ line.

central Arctic. There is a cyclonic anomaly over the central North Atlantic that extends into Europe and over northeastern Russia. These responses are generally small in magnitude but show some regions of statistical significance at the $95 \%$ level. This response is equivalently barotropic, as Z500 (Fig. 10f) has a similar spatial pattern. The Z500 pattern projects onto the negative phase of the summer North Atlantic Oscillation (SNAO; Folland et al. 2009). A negative phase of the SNAO implies that northwestern Europe will experience relatively cyclonic conditions and as a result will likely experience heavy rainfall events (Folland et al. 2009). In the recent low-ice period (2007-14) there have been a number of years in which the summer circulation projected onto the negative phase of the SNAO (Petrie et al. 2015); in many of these years northwestern Europe has experienced extreme flooding events (Blackburn et al. 2008; Folland et al. 2009; Screen 2013). Studies by Balmaseda et al. (2010), Screen (2013), Knudsen et al. (2015), and Petrie et al. (2015) have suggested that the decline in Arctic sea ice and associated changes in SSTs may be responsible for the observed negative SNAO. Petrie et al. (2015) suggested that the decline in sea ice in the Labrador Sea region leads to warming in the lower free troposphere; through thermal wind balance this implies that there is a weakening of the low-level jet over North America. Downstream there is a cyclonic response over northwestern Europe, consistent with Rossby wave propagation. The results of this coupled experiment are consistent with this mechanism. There is a weakening of the zonal winds on the poleward flank of the low-level jet over the North Atlantic and a strengthening on the equatorward flank (Fig. 10k), consistent with an equatorward shift of the eddy-driven jet and a negative phase of the SNAO. The reduced atmospheric meridional temperature gradient results in an elongated zonal Atlantic storm track (not shown), as is associated with a negative phase of the SNAO (Dong et al. 2013). The cyclonic response in JJ over northwestern Europe has approximately the same magnitude as in Petrie et al. (2015). The anticyclonic response in $\mathrm{JJ}$ over Greenland is approximately 2 times greater than in Petrie et al. (2015), indicating that coupled processes are important in capturing the magnitude of the anticyclonic response over Greenland.

In AS, ON, and DJ there are cyclonic anomalies over the ice loss regions of Hudson Bay and the Labrador, Beaufort, Chukchi, East Siberian, and Laptev Seas (Figs. 10b-d). In these regions there is an increase in SAT due to a positive heat flux from the ocean to the atmosphere (see Figs. 5l,q); therefore the cyclonic anomalies are consistent with surface heat lows. Over the central Arctic, the atmospheric responses are baroclinic since the Z500 responses are generally anticyclonic (Fig. 10g). Over the North Pacific and North Atlantic the circulation responses are equivalently barotropic, though in general the circulation responses outside of the central Arctic are not statistically significant in AS, ON, and DJ. The lack of statistically significant responses in DJ implies that any impact that Arctic sea ice loss may have on the large-scale circulation in DJ is small in comparison with natural variability. There is a statistically significant response over the North Atlantic in ON where there is a cyclonic response in MSLP and a dipole of cyclonic and anticyclonic responses in Z500. Consistently, there is also significant response in the 
a $\quad \mathrm{JJ}$

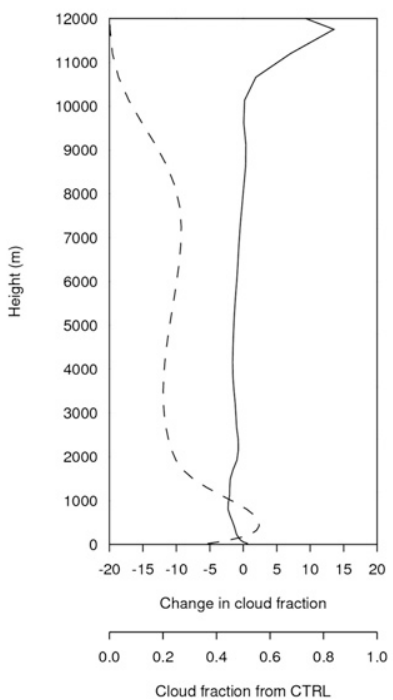

b

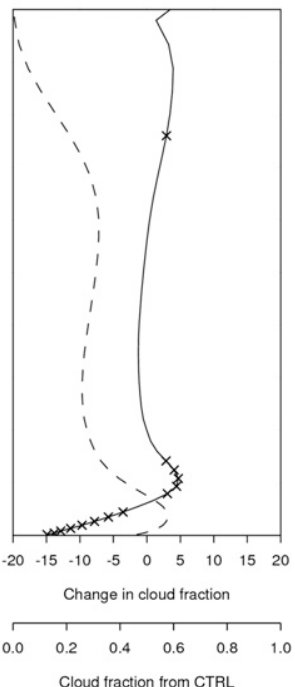

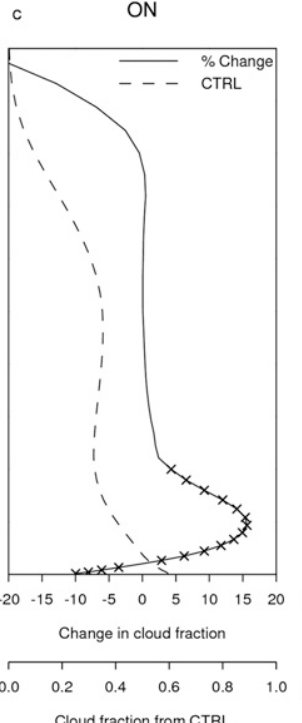

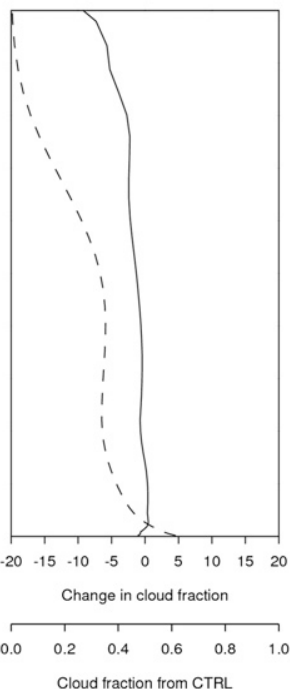

e FM

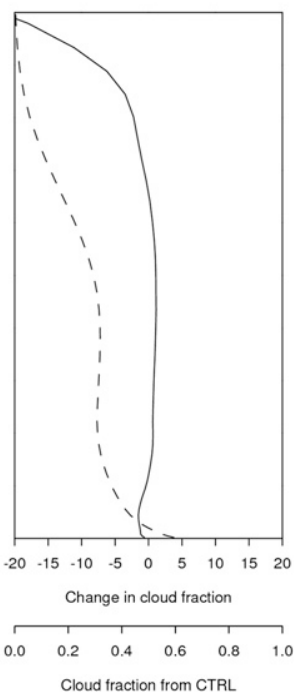

FIG. 8. Two-monthly means of mean Arctic $\left(70^{\circ}-90^{\circ} \mathrm{N}\right)$ fractional cloud cover responses as a percentage difference from CTRL (solid line). The dashed line is the ensemble mean of the CTRL mean Arctic $\left(70^{\circ}-90^{\circ} \mathrm{N}\right)$ fractional cloud cover where the lower axis denotes the scale. Crosses denote statistically significant responses at the $95 \%$ level from a Student's $t$ test.

Atlantic eddy-driven jet, with a weakening of the zonal winds on the poleward flank and a strengthening on the southern flank of the jet. The magnitude of this response is approximately $10 \%$ of the mean state. In ON the ocean-to-atmosphere heat flux is greatest, resulting in a large $(\sim 8 \mathrm{~K})$ increase in SAT (Figs. $5 \mathrm{~m}, \mathrm{r})$. Therefore in $\mathrm{ON}$ there is a reduction in the large-scale meridional temperature gradient. Through thermal wind balance this results in a southward shift of the Atlantic eddydriven jet (Fig. 10m), which is consistent with the coupled model experiment of Deser et al. (2015).

In February-March (FM) there is a cyclonic MSLP anomaly over northern Europe and Siberia (Fig. 10e) that is equivalently barotropic (Fig. 10j), though it is not significant in the Z500 field. In the Z500 field there is a significant cyclonic anomaly over southwestern North America and significant anticyclonic anomalies over North Africa and southern Europe. The low-level jet (Fig. 10o) shows a weakening on the northern flank on the leeward side of the Rocky Mountains and a strengthening on the equatorward flank in the eastern North Atlantic.

Some previous studies (e.g., Magnusdottir et al. 2004; Honda et al. 2009) have found that anomalously low Arctic sea ice conditions in autumn could lead to a negative NAO in the following winter. In this study no
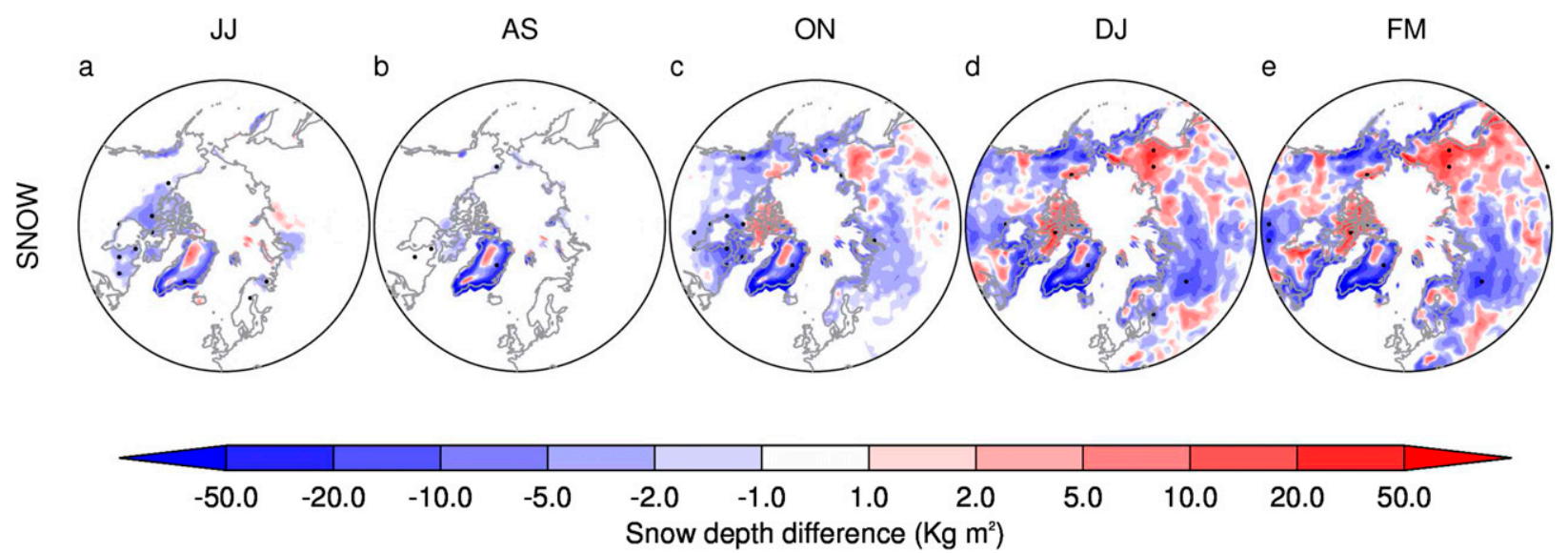

FIG. 9. Two-monthly means of the Northern Hemisphere snow responses from $45^{\circ}-90^{\circ} \mathrm{N}$. Stippling indicates where the response is significant at the $95 \%$ level from a Student's $t$ test. 

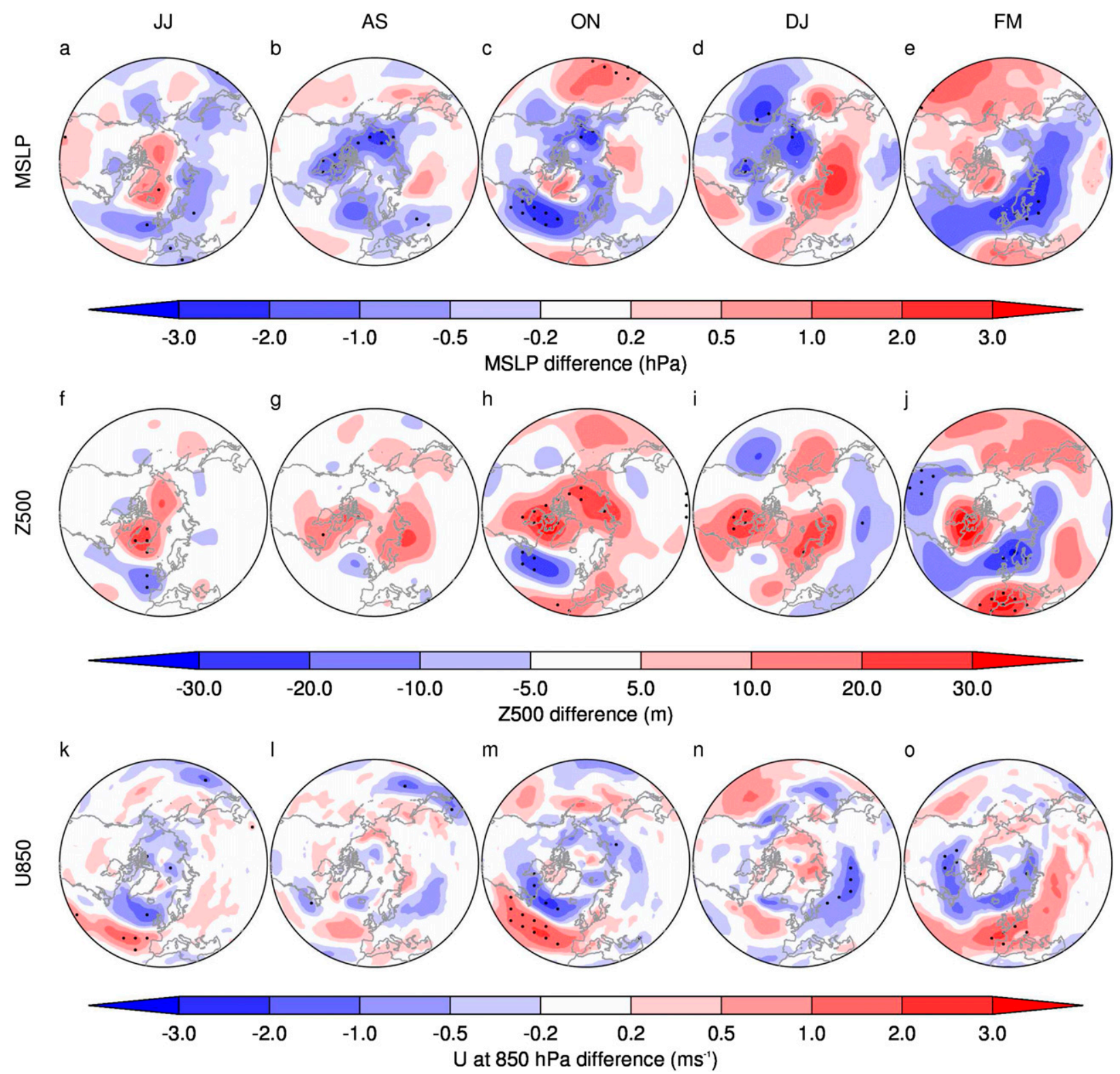

FIG. 10. Two-monthly means of model responses (PERT - CTRL) for (a)-(e) MSLP, (f)-(j) geopotential height at $500 \mathrm{hPa}$, and (k)-(o) zonal wind at $850 \mathrm{hPa}$ from $30^{\circ}$ to $90^{\circ} \mathrm{N}$. Stippling indicates where the response is significant at the $95 \%$ level from a Student's $t$ test.

preferred phase of the NAO (or AO) in winter is observed. This indicates that the winter circulation response to low Arctic sea ice conditions in the preceding autumn is small when compared with natural variability, which is consistent with Screen et al. (2013) and Petrie et al. (2015).

\section{Summary and conclusions}

In this study the effects of an idealized loss of Arctic sea ice have been investigated using a state-of-the-art fully coupled climate model. Two 30-member ensembles of model integrations, each of one year in length beginning on 1 April, were performed. The integrations start from a previously spun-up integration of the Met Office Unified Model. The control (CTRL) and perturbation (PERT) experiments differ only in the initial conditions of sea ice thickness (SIT) distributions on 1 April; the initial conditions of sea ice concentration (SIC) are the same in both CTRL and PERT. In PERT the sea ice melts during the annual cycle to give a sea ice minimum that approximates the recently observed anomalously low sea ice cover of 2007 or 2012. This study, in contrast to most previous modeling studies, utilizes a fully coupled climate model. It is also unique in 
its experimental design, applying a perturbation to the SIT field to isolate the impacts of Arctic sea ice decline on the large-scale atmospheric circulation while accounting for ocean-atmosphere interactions. The main conclusions are as follows:

- There are both local and remote sea surface temperature (SST) responses in the perturbation experiment. Where the sea ice retreats there are local increases in SSTs of $\sim 3 \mathrm{~K}$. This implies that an atmosphere-only experiment investigating the loss of Arctic sea ice that does not account for a local increase in SST of this order of magnitude will likely underestimate the atmospheric response to a given perturbation in SIC. Remote increases in SSTs are seen in the subpolar gyre region of the North Atlantic and in the central North Pacific. In these regions the anomalous surface heat fluxes are from the atmosphere to the ocean, implying that heat released to the atmosphere in regions of sea ice loss is exported out of the Arctic where it warms the ocean.

- There are both local and remote SAT responses in the perturbation experiment. In the central Arctic basin where the SIT has been reduced large increases in SAT with magnitude $\sim 8-10 \mathrm{~K}$ are seen in late autumn and early winter. Increases in SAT outside of the central Arctic are seen over continental North America with magnitude $\sim 1 \mathrm{~K}$. The spatial distribution of the SAT responses in the model is similar to the changes seen in SAT in the ERA-Interim data. It was found that up to twothirds of the observed increase in SAT in autumn over continental North America in the recent low-ice period may be explained as a response to Arctic sea ice loss.

- There is a significant but weak dynamic response in early summer (June-July) that has a pronounced projection onto the negative phase of the summer NAO, with an associated southward shift of the eddy-driven jet. Consistent with the mechanism proposed by Petrie et al. (2015), sea ice loss in Hudson Bay and the Labrador Sea induces increases in temperature at the surface and vertically into the free troposphere in the Newfoundland region. Through thermal wind balance there is a reduction in the prevailing westerlies and a downstream cyclonic anomaly over northwestern Europe consistent with Rossby wave propagation.

- There is also a southward shift of the eddy-driven jet in late autumn (October-November) associated with a reduction in the meridional temperature gradient.

- In winter there is no evidence that links the loss of Arctic sea ice with a particular phase of the NAO or AO. This implies that the winter circulation response to declines in Arctic sea ice is small compared with natural variability, which is consistent with Screen et al. (2013); Petrie et al. (2015).
The results of this study suggest the response of the atmospheric circulation to Arctic sea ice loss may be very different when ocean-atmosphere coupling is considered. In particular, a more extensive warming of the Northern Hemisphere surface is seen, since the heat lost from regions of Arctic sea ice loss can act to warm the surface at lower latitudes. In turn, this results in a larger response in the atmospheric circulation.

There is very large diversity in the results of atmosphere-only experiments investigating the atmospheric circulation responses to Arctic sea ice loss (Cohen et al. 2014). This diversity is large enough to encompass atmospheric circulation responses with opposite signs. If the Arctic sea ice loss experiment in this study were to be performed in other coupled oceanatmosphere climate models, it is likely that a qualitatively similar response in surface warming would be seen (i.e., the heat lost from the regions of Arctic sea ice loss would act to warm the surface at lower latitudes). Therefore, a question to be addressed is whether the atmospheric circulation responses of coupled climate models to Arctic sea ice loss would produce moreconsistent responses than those currently seen in atmosphere-only experiments.

Future work will investigate the thermodynamic and circulation responses in the ocean within this idealized simulation of Arctic sea ice loss.

Acknowledgments. The authors thank the NERC Arctic Programme and the NERC project TEA-COSI for the financial support of this work and the anonymous reviewers for their helpful comments. Collaborators at the Met Office who assisted with the provision of data and code are gratefully acknowledged. The technical assistance of NCAS-CMS and the Met Office MONSooN team are greatly appreciated. Experimental data can be made available on request.

\section{REFERENCES}

Alexander, M., U. Bhatt, J. Walsh, M. Timlin, J. Miller, and J. Scott, 2004: The atmospheric response to realistic Arctic sea ice anomalies in an AGCM during winter. J. Climate, 17, 890-904, doi:10.1175/1520-0442(2004)017<0890:TARTRA > 2.0.CO;2.

Balmaseda, M. A., L. Ferranti, F. Molteni, and T. Palmer, 2010: Impact of 2007 and 2008 Arctic ice anomalies on the atmospheric circulation: Implications for long-range predictions. Quart. J. Roy. Meteor. Soc., 136, 1655-1664, doi:10.1002/ qj.661.

Blackburn, M., J. Methven, and N. Roberts, 2008: Large-scale context for the UK floods in summer 2007. Weather, 63, 280288, doi:10.1002/wea.322.

Budikova, D., 2009: Role of Arctic sea ice in global atmospheric circulation: A review. Global Planet. Change, 68, 149-163, doi:10.1016/j.gloplacha.2009.04.001. 
Cohen, J., and Coauthors, 2014: Recent Arctic amplification and extreme mid-latitude weather. Nat. Geosci., 7, 627-637, doi:10.1038/ngeo2234.

Collins, M., and Coauthors, 2013: Long-term climate change: Projections, commitments and irreversibility. Climate Change 2013: The Physical Science Basis, T. F. Stocker et al., Eds., Cambridge University Press, 1029-1136.

Comiso, J. C., 2012: Large decadal decline of the Arctic multiyear ice cover. J. Climate, 25, 1176-1193, doi:10.1175/ JCLI-D-11-00113.1.

- C. L. Parkinson, R. Gersten, and L. Stock, 2008: Accelerated decline in the Arctic sea ice cover. Geophys. Res. Lett., 35, L01703, doi:10.1029/2007GL031972.

Dee, D., and Coauthors, 2011: The ERA-Interim reanalysis: Configuration and performance of the data assimilation system. Quart. J. Roy. Meteor. Soc., 137, 553-597, doi:10.1002/ qj. 828 .

Deser, C., G. Magnusdottir, R. Saravanan, and A. Philips, 2004: The effects of North Atlantic SST and sea ice anomalies on the winter circulation in CCM3. Part II: Direct and indirect components of the response. J. Climate, 17, 877-889, doi:10.1175/1520-0442(2004)017<0877:TEONAS >2.0.CO;2.

—, R. Tomas, M. Alexander, and D. Lawrence, 2010: The seasonal atmospheric response to projected Arctic sea ice loss in the late twenty-first century. J. Climate, 23, 333-351, doi:10.1175/2009JCLI3053.1.

_ _ - _ and L. Sun, 2015: The role of ocean-atmosphere coupling in the zonal-mean atmospheric response to Arctic sea ice loss. J. Climate, 28, 2168-2186, doi:10.1175/ JCLI-D-14-00325.1.

Dong, B., R. T. Sutton, T. Woollings, and K. Hodges, 2013: Variability of the North Atlantic summer storm track: Mechanisms and impacts on European climate. Environ. Res. Lett., 8, 034037, doi:10.1088/1748-9326/8/3/034037.

Folland, C. K., J. Knight, H. W. Linderholm, D. Fereday, S. Ineson, and J. W. Hurrell, 2009: The summer North Atlantic Oscillation: Past, present, and future. J. Climate, 22, 1082-1103, doi:10.1175/2008JCLI2459.1.

Francis, J. A., and S. J. Vavrus, 2012: Evidence linking Arctic amplification to extreme weather in mid-latitudes. Geophys. Res. Lett., 39, L06801, doi:10.1029/2012GL051000.

— and - 2015: Evidence for a wavier jet stream in response to rapid Arctic warming. Environ. Res. Lett., 10, 014005, doi:10.1088/1748-9326/10/1/014005.

_ - W. Chan, D. J. Leathers, J. R. Miller, and D. E. Veron, 2009: Winter Northern Hemisphere weather patterns remember summer Arctic sea-ice extent. Geophys. Res. Lett., 36, L07503, doi:10.1029/2009GL037274.

Graversen, R. G., and M. Wang, 2009: Polar amplification in a coupled climate model with locked albedo. Climate Dyn., 33, 629-643, doi:10.1007/s00382-009-0535-6.

Hall, D. K., J. C. Comiso, N. E. DiGirolamo, C. A. Shuman, J. E. Box, and L. S. Koenig, 2013: Variability in the surface temperature and melt extent of the Greenland ice sheet from MODIS. Geophys. Res. Lett., 40, 2114-2120, doi:10.1002/ grl.50240.

Honda, M., J. Inoue, and S. Yamane, 2009: Influence of low Arctic sea-ice minima on anomalously cold Eurasian winters. Geophys. Res. Lett., 36, L08707, doi:10.1029/2008GL037079.

Hunke, E., and W. Lipscomb, 2008: CICE: The Los Alamos sea ice model, documentation and software user's manual, version 4.0. Los Alamos National Laboratory Tech. Rep. LA-CC-06$012,73 \mathrm{pp}$.
Jaiser, R., K. Dethloff, D. Handorf, A. Rinke, and J. Cohen, 2012: Impact of sea ice cover changes on the Northern Hemisphere atmospheric winter circulation. Tellus, 64A, 11595, doi:10.3402/tellusa.v64i0.11595.

Knudsen, E. M., Y. J. Orsolini, T. Furevik, and K. I. Hodges, 2015: Observed anomalous atmospheric patterns in summers of unusual Arctic sea ice melt. J. Geophys. Res. Atmos., 120, 2595-2611, doi:10.1002/2014JD022608.

Laxon, S., and Coauthors, 2013: CryoSat-2 estimates of Arctic sea ice thickness and volume. Geophys. Res. Lett., 40, 732-737, doi:10.1002/grl.50193.

Liu, J., J. A. Curry, H. Wang, M. Song, and R. Horton, 2012: Impact of declining Arctic sea ice on winter snowfall. Proc. Natl. Acad. Sci. USA, 109, 4074-4079, doi:10.1073/pnas.1114910109.

Madec, G., 2008: NEMO ocean engine. L'Institut Pierre-Simon Laplace Tech. Rep. 27, 300 pp.

Magnusdottir, G., C. Deser, and R. Saravanan, 2004: The effects of North Atlantic SST and sea ice anomalies on the winter circulation in CCM3. Part I: Main features and storm track characteristics of the response. J. Climate, 17, 857-876, doi:10.1175/1520-0442(2004)017<0857:TEONAS > 2.0.CO;2.

NSIDC, 2012: Arctic sea ice news and analysis. Accessed March 2015. [Available online at http://nsidc.org/arcticseaicenews/.]

Overland, J., K. Wood, and M. Wang, 2011: Warm Arctic-Cold continents: Climate impacts of the newly open Arctic Sea. Polar Res., 30, 15787, doi:10.3402/polar.v30i0.15787.

Palmer, M. D., and K. Haines, 2009: Estimating oceanic heat content change using isotherms. J. Climate, 22, 4953-4969, doi:10.1175/2009JCLI2823.1.

Peings, Y., and G. Magnusdottir, 2014: Response of the wintertime Northern Hemisphere atmospheric circulation to current and projected Arctic sea ice decline: A numerical study with CAM5. J. Climate, 27, 244-264, doi:10.1175/ JCLI-D-13-00272.1.

Perovich, D. K., J. A. Richter-Menge, K. F. Jones, and B. Light, 2008: Sunlight, water, and ice: Extreme Arctic sea ice melt during the summer of 2007. Geophys. Res. Lett., 35, L11501, doi:10.1029/2008GL034007.

Petrie, R. E., L. C. Shaffrey, and R. T. Sutton, 2015: Atmospheric response in summer linked to recent Arctic sea ice loss. Quart. J. Roy. Meteor. Soc., 141, 2070-2076, doi:10.1002/qj.2502.

Polyakov, I. V., J. Walsh, and R. Kwok, 2012: Recent changes of Arctic multiyear sea ice coverage and the likely causes. Bull. Amer. Meteor. Soc., 93, 145-151, doi:10.1175/BAMS-D-11-00070.1.

Porter, D., J. Cassano, and M. Serreze, 2012: Local and large-scale atmospheric responses to reduced Arctic sea ice and ocean warming in the WRF model. J. Geophys. Res., 117, D11115, doi:10.1029/2011JD016969.

Sarafanov, A., A. Falina, A. Sokov, and A. Demidov, 2008: Intense warming and salinification of intermediate waters of southern origin in the eastern subpolar North Atlantic in the 1990s to mid-2000s. J. Geophys. Res., 113, C12022, doi:10.1029/ 2008JC004975.

Schweiger, A., R. Lindsay, J. Zhang, M. Steele, H. Stern, and R. Kwok, 2011: Uncertainty in modeled Arctic sea ice volume. J. Geophys. Res., 116, C00D06, doi:10.1029/2011JC007084.

Scinocca, J., D. Reader, M. Plummer, P. Sigmond, P. Kushner, T. G. Shepherd, and R. Ravishankara, 2009: Impact of sudden Arctic sea-ice loss on stratospheric polar ozone recovery. Geophys. Res. Lett., 36, L24701, doi:10.1029/2009GL041239.

Screen, J., 2013: Influence of Arctic sea ice on European summer precipitation. Environ. Res. Lett., 8, 044015, doi:10.1088/ 1748-9326/8/4/044015. 
, and I. Simmonds, 2013: Exploring links between Arctic amplification and mid-latitude weather. Geophys. Res. Lett., 40, 959-964, doi:10.1002/grl.50174.

_, _ - C. Deser, and R. Tomas, 2013: The atmospheric response to three decades of observed arctic sea ice loss. J. Climate, 26, 1230-1248, doi:10.1175/JCLI-D-12-00063.1.

Seierstad, I. A., and J. Bader, 2009: Impact of a projected future Arctic sea ice reduction on extratropical storminess and the NAO. Climate Dyn., 33, 937-943, doi:10.1007/ s00382-008-0463-x.

Serreze, M., and R. G. Barry, 2005: The Arctic Climate System. Cambridge University Press, $385 \mathrm{pp}$.

— , and R. Barry, 2011: Processes and impacts of Arctic amplification: A research synthesis. Global Planet. Change, 77, 8596, doi:10.1016/j.gloplacha.2011.03.004.

Shaffrey, L., and R. T. Sutton, 2006: Bjerknes compensation and the decadal variability of the energy transports in a coupled climate model. J. Climate, 19, 1167-1181, doi:10.1175/ JCLI3652.1.

Singarayer, J., J. Bamber, and P. Valdes, 2006: Twenty-first-century climate impacts from a declining Arctic sea ice cover. J. Climate, 19, 1109-1125, doi:10.1175/JCLI3649.1.

Smedsrud, L. H., and Coauthors, 2013: The role of the Barents Sea in the Arctic climate system. Rev. Geophys., 51, 415-449, doi:10.1002/rog.20017.

Stroeve, J. C., M. C. Serreze, M. M. Holland, J. E. Kay, J. Malanik, and A. P. Barrett, 2012: The Arctic's rapidly shrinking sea ice cover: a research synthesis. Climatic Change, 110, 1005-1027, doi:10.1007/s10584-011-0101-1.

Tang, Q., X. Zhang, X. Yang, and J. A. Francis, 2013: Cold winter extremes in northern continents linked to Arctic sea ice loss. Environ. Res. Lett., 8, 014036, doi:10.1088/1748-9326/8/1/014036.

$\longrightarrow,-$, and J. A. Francis, 2014: Extreme summer weather in northern mid-latitudes linked to a vanishing cryosphere. Nat. Climate Change, 4, 45-50, doi:10.1038/nclimate2065.

Vihma, T., 2014: Effects of Arctic sea ice decline on weather and climate: A review. Surv. Geophys., 35, 1175-1214, doi:10.1007/ s10712-014-9284-0.

Walsh, J., 2013: Melting ice: What is happening to Arctic sea ice, and what does it mean for us? Oceanography, 26, 171-181, doi:10.5670/oceanog.2013.19.

Wang, C., L. Zhang, S.-K. Lee, L. Wu, and C. R. Mechoso, 2014: A global perspective on CMIP5 climate model biases. Nat. Climate Change, 4, 201-205, doi:10.1038/nclimate 2118.

Williams, K., and Coauthors, 2015: The Met Office Global Coupled model 2.0 (GC2) configuration. Geosci. Model Dev., 8, 521565, doi:10.5194/gmdd-8-521-2015.

Winton, M., 2006: Amplified Arctic climate change: What does surface albedo feedback have to do with it? Geophys. Res. Lett., 33, L03701, doi:10.1029/2005GL025244.

Zhang, J., and D. Rothrock, 2003: Modeling global sea ice with a thickness and enthalpy distribution model in generalized curvilinear coordinates. Mon. Wea. Rev., 131, 845-861, doi:10.1175/1520-0493(2003)131<0845:MGSIWA >2.0.CO;2. 